\title{
REVIEW \\ Preleukemia: one name, many meanings
}

\author{
HP Koeffler ${ }^{1,2,3}$ and G Leong ${ }^{2}$
}

Definition of preleukemia has evolved. It was first used to describe the myelodysplastic syndrome (MDS) with a propensity to progress to acute myeloid leukemia (AML). Individuals with germline mutations of either RUNX1, CEBPA, or GATA2 can also be called as preleukemic because they have a markedly increased incidence of evolution into AML. Also, alkylating chemotherapy or radiation can cause MDS/preleukemia, which nearly always progress to AML. More recently, investigators noted that AML patients who achieved complete morphological remission after chemotherapy often have clonal hematopoiesis predominantly marked by either DNMT3A, TET2 or IDH1/2 mutations, which were also present at diagnosis of AML. This preleukemic clone represents involvement of an early hematopoietic stem cells, which is resistant to standard therapy. The same clonal hematopoietic mutations have been identified in older 'normal' individuals who have a modest increased risk of developing frank AML. These individuals have occasionally been said, probably inappropriately, to have a preleukemia clone. Our evolving understanding of the term preleukemia has occurred by advancing technology including studies of $\mathrm{X}$ chromosome inactivation, cytogenetics and more recently deep nucleotide sequencing.

Leukemia (2017) 31, 534-542; doi:10.1038/leu.2016.364

\section{PRELEUKEMIA ASSOCIATED WITH MYELODYSPLASTIC SYNDROME}

The term 'preleukemia' has undergone a major evolution since it was first used in 1953 by Block et al. ${ }^{1}$ At that time, the term referred to the heterogeneous group of hematopoietic disorders associated with a block in myeloid differentiation and chronic cytopenias. We now call these disorders, myelodysplastic syndromes (MDS). ${ }^{2-9}$ Prevalence of these abnormalities is markedly increasing as our population ages; about 75 new patients per 100000 individuals per year over the age of 65 years develop MDS. About $20-30 \%$ of these individuals do indeed progress to acute myeloid leukemia (AML); and thus, these individuals might justifiably be known as preleukemic.

In the late 1960s and 1970s, one of the prominent advances in our understanding of MDS/AML was the concept that the MDS/ leukemic event occurred in 1 stem cell, which had a hematopoietic growth advantage causing a clonal population of MDS/ leukemic cells. This insight was based on the observation of $X$-inactivation in females. ${ }^{10,11}$ Females have two $X$ chromosomes; between the 4th and 16th cell stage of blastogenesis, each cell stochastically inactivates either its maternal or paternal $X$ chromosome. A number of methods have evolved to determine which $X$ chromosome has been inactivated. ${ }^{12,13}$ The initial approach was pioneered by Ernest Beutler who utilized G6PD isoenzymes. ${ }^{14-16}$ Over the years, additional methods were developed to identify X-inactivation in females, with one of the most versatile taking advantage of 2 features: cytosine methylation of the inactive $X$ chromosome and different numbers of CAG trinucleotides within the promoter region of the androgen receptor, which resides on the $X$ chromosome. ${ }^{17}$ This technique allows interrogation of almost all females as opposed to a small population of predominantly African Americans with G6PD isoenzymes. Philip Fialkow's group showed clonal hematopoiesis occurred in a number of hematopoietic diseases including chronic myelogenous leukemia, acute lymphocytic leukemia and AML. ${ }^{18}$ Also, Fialkow noted that in many cases of $A M L$, the clonality occurred in the myeloid compartment and not the lymphoid compartment. MDS, in contrast, appeared to have an identical clonality of both the myeloid and lymphoid compartments, albeit the myeloid compartment appeared to have a major growth advantage. ${ }^{19}$ This suggested that the MDS clone initiated in a very early hematopoietic stem cell.

With the era of massively parallel nucleotide sequencing, we have a fairly clear idea of the major mutations that affect patients who have MDS, who evolve from MDS to AML (secondary AML, SAML) and those with de novo AML (Table 1). ${ }^{4,5,20-28}$ Nine genes occur more frequently in MDS than de novo AML (Table 1) including four spliceosome genes that are mutated in $60-70 \%$ of MDS cases, but these latter genes are mutated in fewer than $5-10 \%$ of de novo AML cases. ${ }^{29}$ These mutant genes are involved in ineffective dysplastic hematopoiesis, not frank AML.

Mutations that are often observed in de novo AML are known as Driver or pan-AML mutations including mutations of NPM1, FLT3, IDH1, N/KRAS, RUNX1, CEBPA, WT1, PTPN11, c-KIT. For example, NPM1 is rarely mutated in MDS, but occurs in $27 \%$ of de novo AML cases. Likewise, chromosomal translocations (often a fusion of a transcription factor gene with another gene) occur frequently in de novo AML (18\%). Examples include fusion of genes such as RUNX1 with ETO, PML with RARA, CBFB with MYHII, as well as fusion of $M L L$ with various partner genes, which only rarely occur in MDS (4\%). ${ }^{30}$ These Driver mutations produce a major block in differentiation providing a proliferative advantage to this clone of cells. $^{30}$

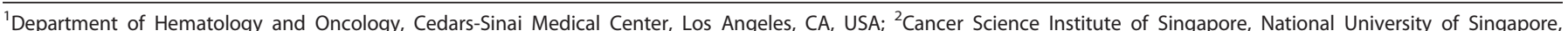

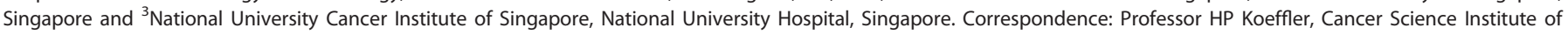
Singapore, National University of Singapore. 14 Medical Drive, MD6, Centre for Translational Medicine, \#12-01, Singapore 117599, Singapore.

E-mail: phillip_koeffler@nuhs.edu.sg or H.Koeffler@cshs.org.

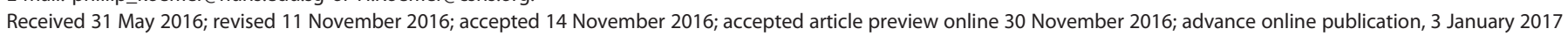


Table 1. Exome sequencing: mutational defects in MDS and SAML versus de novo AML

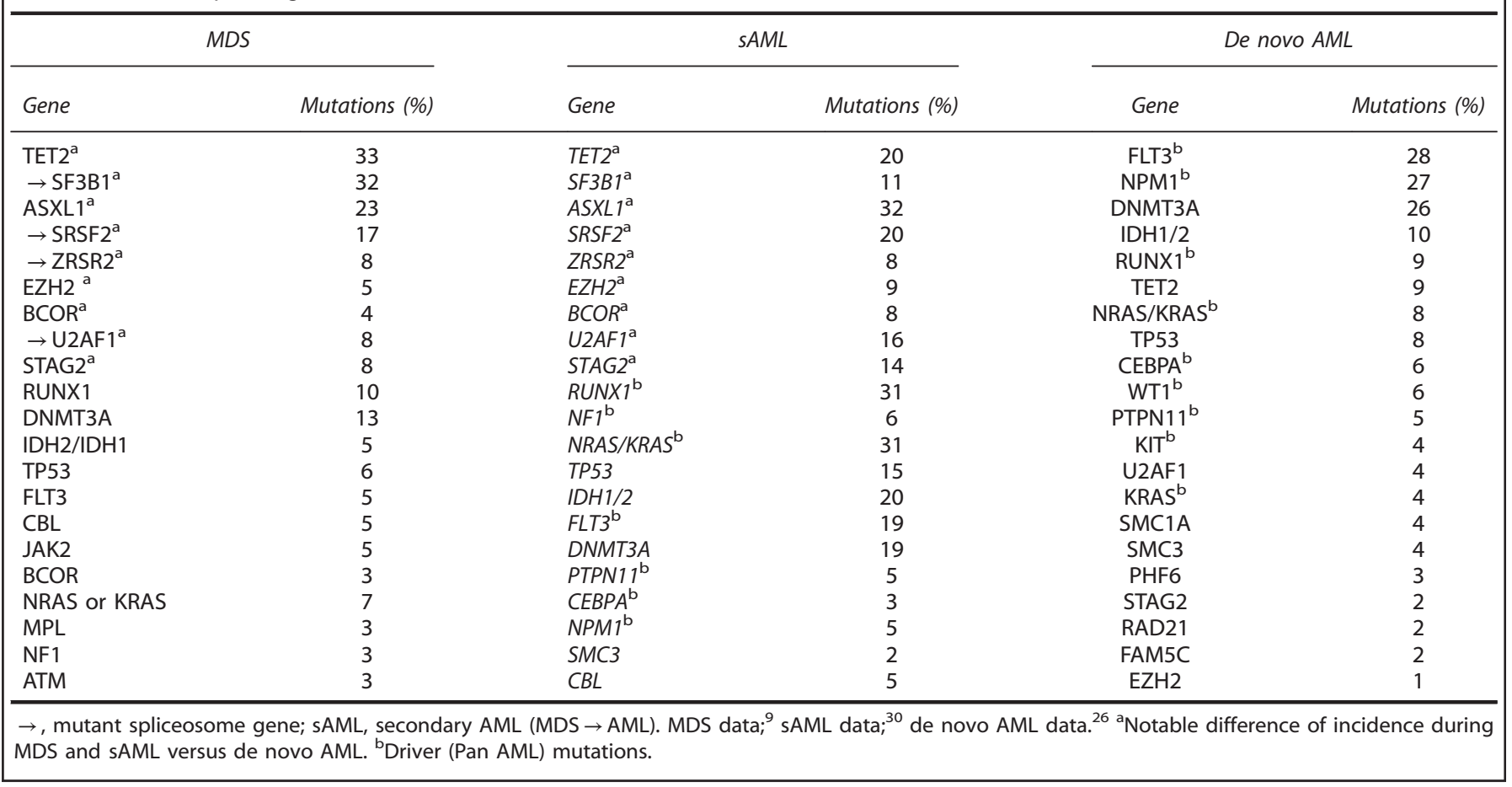

Because cases of sAML evolves from MDS, these cells often contained genes mutated in MDS (Table 1). ${ }^{30}$ Driver (pan-AML) mutations are gained as MDS evolves to sAML. ${ }^{30}$ Of interest, individuals with SAML achieve complete remission only about $50 \%$ of the time and their event-free survival (EFS) is 4.2 months. In contrast, $92 \%$ of de novo AML patients enter a complete remission, and their EFS is $~ 15.7$ months. ${ }^{30}$

\section{OLIGOCLONAL HEMATOPOIESIS: NORMAL AGING VERSUS PRELEUKEMIC CLONE}

Analysis of $X$ chromosome inactivation discovered skewing of $X$ chromosome inactivation (also known as Lyonization). ${ }^{31-34}$ $\mathrm{X}$-inactivation during blastogenesis usually results in equal inactivation of the maternal and paternal X chromosomes in the female. Skewing represents unequal distribution of cells expressing either the paternal and maternal allele of the female $X$ chromosome. It can occur during early embryogenesis, but rarely deviates $>10 \%$. However, $X$ chromosomal skewing increases with age approaching $20 \%$ of those who are $28-32$ years old, and $40 \%$ of those $\geqslant 60$ years. ${ }^{10,12,13,32-34}$ A study in normal females $\geqslant 75$ of age found that $56 \%$ of individuals had skewing of neutrophils and $40 \%$ had skewing of T-lymphocytes. ${ }^{34}$ Thus, older individuals have hematopoietic cells that favor usage of one $X$ allele. This has been explained by unequal exhaustion of hematopoietic stem cells as individuals age. This observation was buttress by genomically marking murine hematopoietic stem cells and using them for complete hematopoietic transplantation. Multiple clones of hematopoiesis initially developed in these transplanted animals; but as the mice aged, oligoclonal hematopoiesis predominated, suggesting that with age, certain hematopoietic clones can predominate. $^{35}$ of note, this phenomenon was not noted in humans who underwent hematopoietic transplantation. ${ }^{36}$

SNP-Chip analysis of peripheral blood of 50000 normal individuals showed that copy-number changes in the genome increased with increasing age; $>0.5 \%$ of individuals from birth to 50 years of age had copy number alterations; but after age 50 years, the rate rose to about $2-3 \% .^{37}$ These copy-number changes often occurred in genes that also are abnormal in MDS and AML. ${ }^{37}$ These individuals with copy-number changes had a 10-fold increased risk of developing MDS or AML. ${ }^{37}$

Recently, a number of studies using high throughput nucleotide sequencing confirmed what had been suggested by studies of skewing of the inactive $\mathrm{X}$-chromosome in normal elderly individuals. On average, a normal appearing 60-, 70- and 90year-old individual has a $5 \%, 10 \%$ and $20 \%$ incidence, respectively, of clonal hematopoiesis as marked by a mutation. ${ }^{38-40} \mathrm{~A}$ recent study of a normal population of 50-60-year-old individuals found with exceptionally deep sequencing that clonal hematopoiesis occurred in $95 \%$ of individuals as marked by a mutation of either DNMT3A or TET2. ${ }^{41}$ An interesting, unifying study found TET2 mutations in the blood of ten of 182 elderly 'normal' women who also had chromosomal skewing of the $\mathrm{X}$ chromosome. In contrast, 105 normal women of the same age without X-chromosome skewing, had no TET2 mutations. ${ }^{42}$ Mutation of DNMT3A occurs about fivefold more frequently in the normal elderly individuals than mutations of either TET2, IDH1/2, AXSL1, JAK2, SRSF2 or SF3B1 (to name a few). Many of these mutations of the normal elderly are the same as those in the preleukemic clone identified in complete remission of $S A M L$, or found in the very early hematopoietic stem cells in individuals with either MDS or AML (both to be discussed). ${ }^{38-40,43}$ The base change of these mutations was most commonly cytosine to thymine transition, which is a somatic mutational signature of aging. Usually only one gene and on rare occasions two or three genes are mutated; these additional mutations occur more frequently as the 'normal' individual becomes older. ${ }^{38-40}$ On average, $<20 \%$ and more often $<3 \%$ of either the peripheral blood or marrow cells are part of the mutant hematopoietic clone in these elderly individuals (also called variant allele frequency (VAF)).

For lack of a better nomenclature, this hematopoietic clone in the elderly has occasionally been called an age-related preleukemic clone; this is usually a misnomer. About 0.5 to $1 \%$ of these individuals per year developed MDS/AML (hazard ratio 11.112.9). ${ }^{38,39}$ The greater the number of different mutations or the greater the contribution (VAF) of the mutant clone, the greater the 
536

chance to evolve into MDS/AML (for example, if the mutant clone constitutes $>10 \%$ of the hematopoietic population, these individuals have at least a $1 \%$ risk per year of developing $A M L^{39}$ ). Acquisition of a Driver (pan-AML) mutation(s) is required for development of AML in these individuals with morphologically normal marrow cells. These genes behave as the 'gatekeepers' of leukemogensis providing, when mutated, the needed stimulus for establishment of frank AML.

Thus as humans age, they often develop a hematopoietic clone carrying a mutation of at least either DNMT3A, ASXL1, TET2 or IDH2, but only a small minority of these individuals actually develop myeloid malignancies. These Driver mutations provide a competitive advantage to the hematopoietic stem cells compared with normal hematopoiesis. Whether this mutant stem cell pool is more receptive to secondary mutations requires further study.

Analogous phenomenon occur in the lymphoid system. Monoclonal gammopathy of unknown significance (MGUS) features a small accumulation of plasma cells producing a monoclonal immunoglobulin. ${ }^{44}$ The aberrant clone of plasma cells infrequently ( $1 \%$ per year) progresses to multiple myeloma. Likewise, a clonal mature B-cell population can develop in older individuals, which rarely progresses to chronic lymphocytic leukemia. ${ }^{45}$ Incidence of all three of these clonal hematopoietic conditions increase with age. Clonal abnormalities have been noted in other tissue which otherwise appear normal. For example, the normal sun-exposed eyelid frequently has mutations including NOTCH1, NOTCH2, NOTCH3, FAT1, TP53 and RBM10; some of these mutations are associated with clonal expansion of these skin cells. ${ }^{46}$ Also, we and others noted years ago that the normal appearing colon and lung near the tumor can harbored genomic alterations (for example, aneuploidy, RAS mutations). ${ }^{47,48}$ These too represent a precancerous genomic abnormality.

\section{PRELEUKEMIA: GERMLINE MUTANT HEMATOPOIETIC CLONE}

Twins studies have suggested familial clustering of $A M L ;{ }^{49,50}$ and a large analysis of over 24000 first-degree relatives of about 7000 patients with AML noted that if the proband develops MDS/AML before the age of 25 years, the first-degree relative has an increased risk of MDS and AML. ${ }^{51}$ Individuals with inherited germline mutations of one of several transcription factors (RUNX1, GATA2 or (EBPA) have an increased propensity to develop AML over their life. ${ }^{52-56}$ Other inherited germline that can also predispose to MDS includes Diamond-Blackfan anemia (20\% risk of $\mathrm{MDS} / \mathrm{AML}$ ), dyskeratosis congenita (disorder of telomere maintenance, 30\% risk MDS/AML), Fanconi anemia ( $40 \%$ risk), severe congenital neutropenia (20-40\% risk), ShwachmanDiamond syndrome (10-35\% risk), mutations of the SRP72 gene (increased risk of aplastic anemia or MDS), Bloom syndrome $(25 \%$ risk for MDS/AML), Li-Fraumeni syndrome (p53 mutation) (5-7\% risk) and familial monosomy $7 . .^{57-59}$ For each of these inherited germline mutation, their progression to frank $A M L$ requires the clonal acquisition of addition genetic mutations. ${ }^{60}$

Familial AML with germline mutant CEBPA (OMIM 11697) is inherited (autosomal dominant) and has nearly complete penetrance for development of AML. ${ }^{54,56} \mathrm{AML}$ can develop anytime from the age of 1 year to old age. The AML is usually associated with biallelic CEBPA mutations, usually the first mutation is germline and often at the $5^{\prime}$ end of the gene, and the second mutation occurs in the second allele often in the $3^{\prime}$ region of the gene. This is similar to what is observed in those with somatic mutations of CEBPA (de novo AML). CEBPA is critical for myeloid proliferation and granulocytic differentiation. Most of these patients have a normal karyotype when they develop AML; and they have a relatively favorable prognosis with $50-60 \%$ that may be cured. The AML is often FAB subtype $M 1$ or $M 2$, with aberrant CD7 expression on the blast cells and often a N-RAS mutation present in the blast cells. As expected, siblings of the proband with the germline CEBPA mutation have a $50 \%$ risk of also carrying the mutation.

Familial platelet disorder (FPD), (OMIM 601399) with a propensity to AML is caused by a germline mutation of RUNX1. The RUNX1 gene is important for myeloid proliferation and differentiation; and its alteration in FPD is either a deletion, a loss of function missense mutation or occasionally a dominantnegative missense mutation. These individuals often have a low peripheral blood platelet count, a functional platelet disorder and GCSF hypersensitivity of their myeloid cells. ${ }^{52,61}$ The frequency of developing AML with FPD is about $40 \%$, and AML can occur at any age but more often between 40 and 70 years of age.

AML that develops in FPD individuals do not acquire NPM1 or FLT3 mutations, which are frequently found in de novo AML. A recent study found that asymptomatic RUNX1 carriers can harbor additional somatic mutations with a mean VAF varying between 20 and 45\%, suggesting that clonal skewed hematopoiesis frequently precedes the development of overt MDS or AML. ${ }^{60}$ All asymptomatic RUNX1 carriers were less than the age of 50 . By the age of 50 years, clonal hematopoiesis was easily found in $80 \%$ of RUNX1 carriers. $^{60}$ One Japanese study reported that these patients had frequent mutations of the CDC25C gene when they progressed to AML. ${ }^{62}$ However, this mutation could not be detected by other investigators. ${ }^{60,63}$ This could represent ethnic differences. The number of mutations in the blast cells found at the time of AML varies between 8 and 18. The VAF of these mutations in both the MDS and AML phases of FPD were comparable (approximately 15-45\%). ${ }^{60,61,64}$

Another germline alteration is a heterozygous mutation of the transcription factor GATA2. These individuals often have peripheral blood eosinophilia, deficiency of monocytes, B cells and natural killer cells and an increased incidence of non-tuberculosis mycobacteria and other opportunistic infections including papilloma virus. ${ }^{53,55,65-67}$ The syndrome is often called (MonoMAC). These patients in addition can develop leg lymphedema and monosomy 7 (Emberger syndrome). The predilection to develop MDS or AML is about $70 \%$ with a median age of 29 years, but AML can develop over a wide time span (0.4 to 78 years). Their MDS phase is often characterized as chronic myelomonocytic leukemia. The progression to AML is associated with an initial cytopenias often followed by monosomy 7 (30\%) which appears to occur before an ASXL1 mutation (29\% of cases). Interestingly, this latter mutation occurs only in females, who are often young; it is associated with a bad prognosis. ${ }^{68,69}$ Another frequent secondary mutation is NRAS, but other Driver mutations have been noted including RUNX1, STAG2, IDH2, TP53 and SETDB1. Transformation is often to a hypercellular fibrotic AML.

Clearly, more experience is required to determine at what stage these individual with germline preleukemic mutations need aggressive therapy. Monitoring their marrow for the acquisition of additional Driver mutations might prompt initiation of aggressive therapy such as allogenic hematopoietic stem cell transplant. ${ }^{60}$ If a sibling allotransplant is contemplated, germline DNA sequencing of the donor for the germline mutation is required because the sibling has a $50 \%$ chance of also having the germline mutation. The ability to take fibroblasts from patients with germline mutations, induced dedifferentiation to pluripotent stem cells (iPSC), correct the mutation and then induce these cells to differentiate into functional hematopoietic stem cell, has been done. $^{70,71}$ However, to date, full hematopoietic reconstitution in vivo has not been possible using the iPSC technique. Furthermore, gene therapy to repair directly the hematopoietic cells is a distant dream with a multitude of barriers because unlike treating sickle cell anemia or thalassemia, every cell must be corrected. 


\section{THERAPY-RELATED PRELEUKEMIA}

Several types of therapy-(mutagen)-related MDS/AML have been identified. One that almost always has a preleukemic (MDS) phase is associated with exposure to either alkylating agents (85\%), radiation or selected carcinogens, such as benzene. ${ }^{72-74}$ Most frequently an individual with Hodgkin disease, non-Hodgkin disease, breast cancer, multiple myeloma and so on receives an alkylating agent and approximately 4 years later develops MDS. The incidence of therapy-related preleukemia varies from $<1$ to $10 \%$ depending on type of agent administered and the intensity of the therapy for the initial cancer. ${ }^{72,75-78}$ Their preleukemic marrow often $(>70 \%)$ has deletion of either the long arm or the entire chromosome 5 and/or 7; or they develop a complex karyotype ( $\geqslant 3$ abnormalities). ${ }^{75,79-81}$ Some of the frequently mutated genes in this type of preleukemia includes p53, PTPN11 and the $A B C$ family of genes. The $p 53$ mutation often occurs early in the course of MDS. A second group of mutations are commonly associated with secondary AML (Table 1). In contrast to de novo acute leukemia, mutations of NPM1, CEBPA or FLT3 are infrequent. $^{30,72,82-84}$ The RAEB and RAEB-t subgroups are frequently linked to therapy-related preleukmia (73\%). ${ }^{85}$ These individuals almost always progress to AML with a mean duration of the preleukemic phase of 11.2 months. ${ }^{86-88}$ They have a poor prognosis (survival with AML $<6-8$ months). ${ }^{73,75,89}$ Treatment for these individuals when AML develops has a number of clinical challenges including a greater number of co-morbidities, decreased organ reserve from either previous therapy or primary disease and a higher incidence of unfavorable cytogenetic changes. The key prognostic factors in therapy-related MDS/AML are patient's age, performance status and karyotype. Because of their poor outcome, intensive chemotherapy with allogeneic hematopoietic stem cell transplant should be encouraged.

In summary, the development of unexplained pancytopenia and the finding of specific karyotypic abnormalities (loss of chromosome 5 and/or 7 or their long arms in the marrow) in patients who received chemotherapy and/or radiation therapy for another disease about 4 years earlier is pathognomonic of preleukemia. Evolution to overt leukemia is almost universal if the preleukemic individual survives the complications of hemorrhage and infection. Therapy preleukemia can be viewed as an early phase of therapy AML in which the malignant hematopoietic clone is established and becomes predominant.

The second type of therapy-related AML develops in individuals whose initial malignancy was treated with a topoisomerase II inhibitor (for example, etoposide, doxorubicin, mitoxantrone). ${ }^{72,90,91}$ Typical latency period from therapy to AML is a median of 33 months but can be as short as 12 months. The AML often has a chromosomal translocation especially at $11 \mathrm{q} 23$ (MLL gene) or chromosome $21 \mathrm{q} 22$ (RUNX1). The morphologic phenotype often is FAB M4 or M5. These individuals usually do not have a MDS (preleukemic) phase. Overall survival of these individuals after development of $A M L$ is equal to that of a patient with de novo leukemia having the same cytogenetic abnormalities in their AML cells.

\section{PRELEUKEMIA IN MORPHOLOGIC COMPLETE REMISSION AFTER AML CHEMOTHERAPY}

During the 1980s and the early 1990s, studies by Phil Fialkow and Claus Bartram noted that about $1 / 4$ of AML patients who achieved complete morphologic remission by chemotherapy, continued to have an abnormal clone as measured by X-inactivation. ${ }^{31}$ This has been buttress by studies showing strong association between persistent karyotypic markers of AML in first complete morphologic remission. Hence, the term 'preleukemic clone' has been used to describe the loss of the major phenotype of AML (Driver mutations associated with AML blast cells), but where the clonal hematopoiesis persisted, and could evolve into relapse AML. Thus, the term preleukemia is used in a very different context than utilized in the 1950s and 1960s.

High throughput sequencing of $\mathrm{AML}$ samples reinforced the concept that a preleukemic clone can exist at the time of complete morphologic remission after standard aggressive chemotherapy for AML. Individuals whose AML cells at diagnosis had mutations of either DNMT3A, IDH2, TET2, UAF1 or SRSF2 often had the same alteration at complete morphologic remission. ${ }^{92-98}$ In contrast, more classical Driver (pan-AML) mutations such as FLT3, RUNX1, RAS, NPM1, CEBPA and WT1 genes, although present at diagnosis of $A M L$, were no longer found in complete remission. Dr. Ley's group reported that 21/37 individuals whose AML cells carried DNMT3A, TET2 or IDH1/2 mutations at diagnosis, continued to have the same mutation in $>5 \%$ of the hematopoietic cells at complete morphologic remission; but the classical Driver mutations (for example, NPM1, FLT3 and RAS) found at diagnosis, were not detectable at remission. ${ }^{94}$ Of note, if the individual had a persistence of a mutation at complete remission (day 30 after induction therapy), their event-free survival was 6 months and their overall survival was 10 months as compared with an eventfree survival of 18 months and an overall survival of 42 months in individuals with no mutation in the 30-day complete remission marrow.

Another study focused on DNMT3A mutations. The investigators noted that the DNMT3A mutation was often present in the marrow cells in complete morphologic remission at an allele frequency of $1-50 \%$ and could be detected even 8 years after initial complete remission of $\mathrm{AML}$ with no other molecular markers of $\mathrm{AML}$. Likewise, the mutations could be found at a lower allele frequency in $\mathrm{T}$ and $\mathrm{B}$ lymphocytes in the same patients. ${ }^{97}$ The authors concluded that DNMT3A mutations precede NPM1 and FLT3-ITD mutations in AML pathogenesis; and the fact that this mutation can be found in B and T cells suggest that it involves a very early hematopoietic stem cell that can differentiate both into lymphoid and myeloid cells. ${ }^{93,97}$

Dr. Dick's group studied a cohort of individuals whose AML blast cells had mutations of DNMT3A and NPM1 at both diagnosis and relapse. ${ }^{93}$ In morpholoigc complete remission, only the DNMT3A mutation could be found. In a second part of the study, human bone marrow cells at diagnosis of AML (264 samples) were injected into immunodeficient mice (NSG mice). A total of $37 \%$ of samples did not engraft, $40 \%$ of samples recapitulated the AML blasts in the mice; but most interestingly, $23 \%$ of the samples produced multi-lineage engraftment that appeared normal, but continued to have mutations of either DNMT3A or IDH1/2. ${ }^{93}$ This suggests that even at diagnosis of $A M L$, a preleukemic clone exists. Interestingly, the same group also purified different stages of hematopoietic cells at diagnosis of AML whose blasts cells were marked with both DNMT3A and NPM1 mutations. ${ }^{93}$ The very early common hematopoietic progenitors carried the mutation of DNMT3A, but not NPM1. In contrast, the more mature myeloid progenitor cells (granulocyte-monocyte progenitors), as well as the AML blast cells had both the DNMT3A and NPM1 mutations (Figure 1 summarizes these studies).

A very detailed study focused on IDH2 found that about $22 \%$ of individuals with an IDH2 mutant allele at diagnosis of sAML continued to have the mutational clone in complete morphologic remission after chemotherapy; but with marrow transplant, these aberrant alleles were destroyed. ${ }^{98}$ In addition, the VAF of the mutant IDH2 clone exceeded the VAF of the NPM1 or FLT3 clones in frank AML, and the NPM1 and FLT3 clones disappeared with complete remission. Colony assays of CD34+ hematopoietic stem cells and progenitor cells were done in complete remission and $96 \%$ and $50 \%$ of the erythroid and granulocyte macrophage colonies, respectively, had only the IDH2 mutation. Further, colony and single-cell-nucleotide sequencing also confirmed that DNMT3A, TET2 and ASXL1 were early clonal mutations during evolution to AML. ${ }^{99,100}$ 


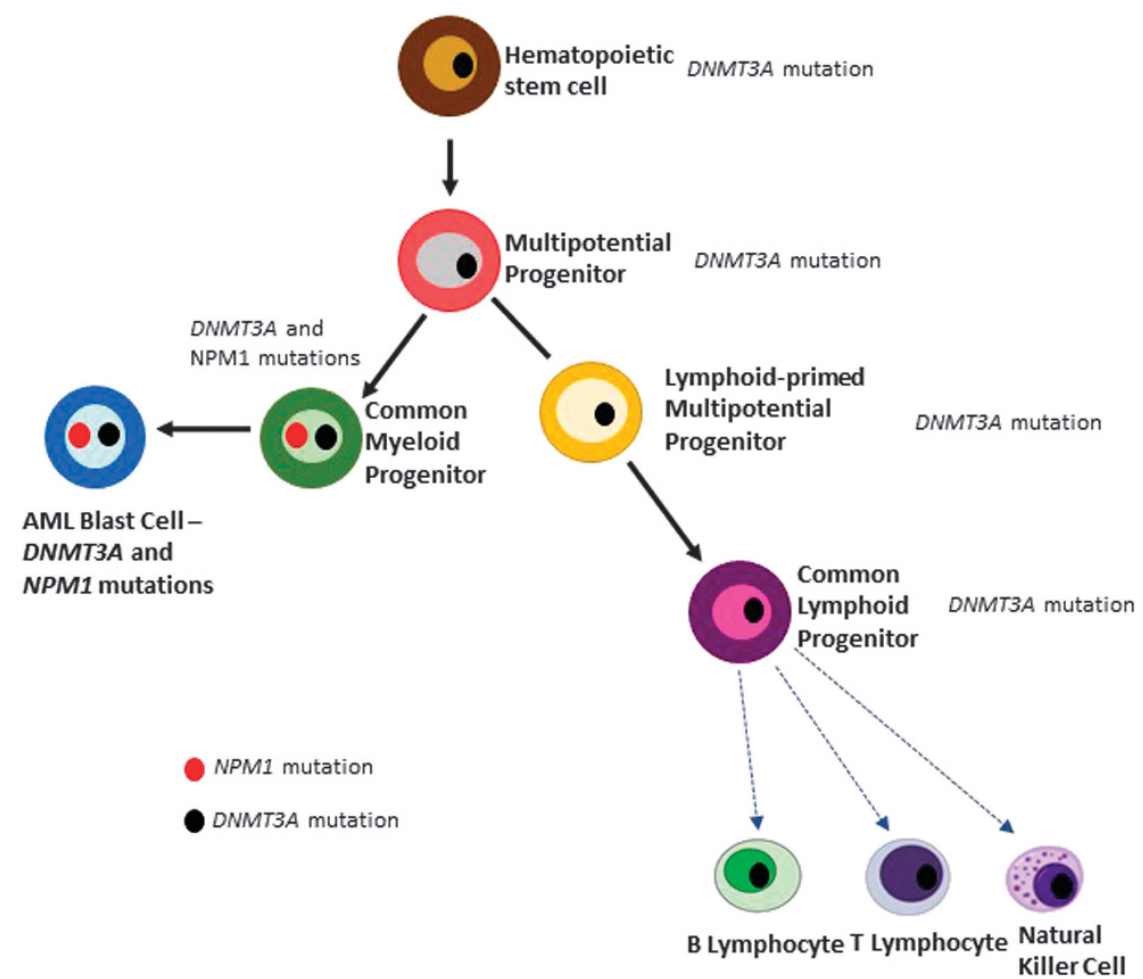

Figure 1. Schematic diagram of the hematopoietic tree with stem cells having a preleukemic mutation (DNMT3A) and blast cells acquiring a Driver (pan-AML) mutation (NPM1 mutation), and retaining the DNMT3A mutations. Black dot, DNMT3A mutation; Red dot, NPM1 mutation. Figure summarizes data by John Dick's lab.93

Interestingly, recent studies found a rapid expansion of a preexisting non-leukemic/preleukemic mutant hematopoietic clone occurred following induction therapy for de novo AML. ${ }^{101,102}$ Investigators discovered that at diagnosis of AML, a small, barely detectable, non-leukemic clone was overshadowed by the leukemic clone. After remission inducing chemotherapy, the non-leukemic/preleukemic clone markedly expanded (VAF of 20-40\%) compared with the normal hematopoietic population. Thus, the non-leukemic/preleukemic mutant clones had a competitive advantage over the normal hematopoietic cells. These studies highlight the importance to distinguish Driverrelated leukemia versus non-leukemic/preleukemic mutant populations when the physician assesses by DNA sequencing the response to induction chemotherapy.

\section{PRELEUKEMIC STEM CELLS AND THERAPEUTIC IMPLICATIONS}

A long-lasting preleukemic (MDS) clone often marked by mutations of either DNMT3A, TET2 IDH1/2 or a spliceosome gene, can have a competitive growth advantage over the normal hematopoietic cells. These mutations can cause ineffective hematopoiesis. This can be followed by a subclone that develops a major Driver mutation (for example, NPM1) or fusion gene, resulting in frank AML with blast cells. These Driver (pan-AML) mutations block differentiation providing these cells with a proliferative advantage and causing life-threatening peripheral blood cytopenias. After ablative chemotherapy accompanied by a complete morphologic remission, the preleukemic clone may persist suggesting that these cells are resistant to standard chemotherapy, but are still able to differentiate to normalappearing mature blood cells. If frank $A M L$ reoccurs, the original or new blastic AML subclone emerges from the preleukemic clone. Event-free survival of individuals with a preleukemic clone at morphologic complete remission, is inferior to those with no preleukemic clone during complete remission. ${ }^{30,94}$ Perhaps, therapeutic intervention might be considered while these patients are in complete morphologic remission if nucleotide monitoring shows the acquisition of a Driver mutation. ${ }^{103}$ This might prompt hematopoietic transplantation before frank AML develops (Figure 2). Timing will be critical because reports have found that the preleukemic clone may be present for 8-10 years without emergence of relapsed blastic AML. Repeat targeted nucleotide sequencing of the marrow may be no more expensive than cytogenetic examination; and in the future sequencing may supplant cytogenetics in define circumstances.

IDH2 mutant AML cells can generate D-2-hydroglycolate (D-2HG) as a marker of the mutation. ${ }^{98}$ The plasma level of this compound is high in AML patients; however, those in complete morphologic remission with a mutant IDH2 clone may also have elevated serum D-2-HG. Therefore, measuring D-2-HG is not a good surrogate for making clinical decisions. ${ }^{98}$ Specific pharmacologic inhibitors of IDH2 have been developed. IDH2 mutation is often in the founder mutant clone; this clone acquires a Driver mutation to develop frank AML. The ability of the IDH2 inhibitor to eliminate the AML or founder clone requires further study.

Of interest, mathematic modeling noted a good correlation between the lifetime risk of developing cancer and the number of stem cell division that specific tissue undergoes during an individual's lifespan. ${ }^{104,105}$ Mutations are passed to daughter cells only at cell division. Normal cells undergo about 1 mutation per $10^{8}$ cell divisions. An estimated 11000 to 22000 early hematopoietic stem cells are present in an individual. This number decreases with age. Indeed, a likely hypothesis is the fewer hematopoietic stem cells that are present as an individual ages, the greater their proliferative pool to maintain normal peripheral blood counts; hence, the greater chance for a mutational 


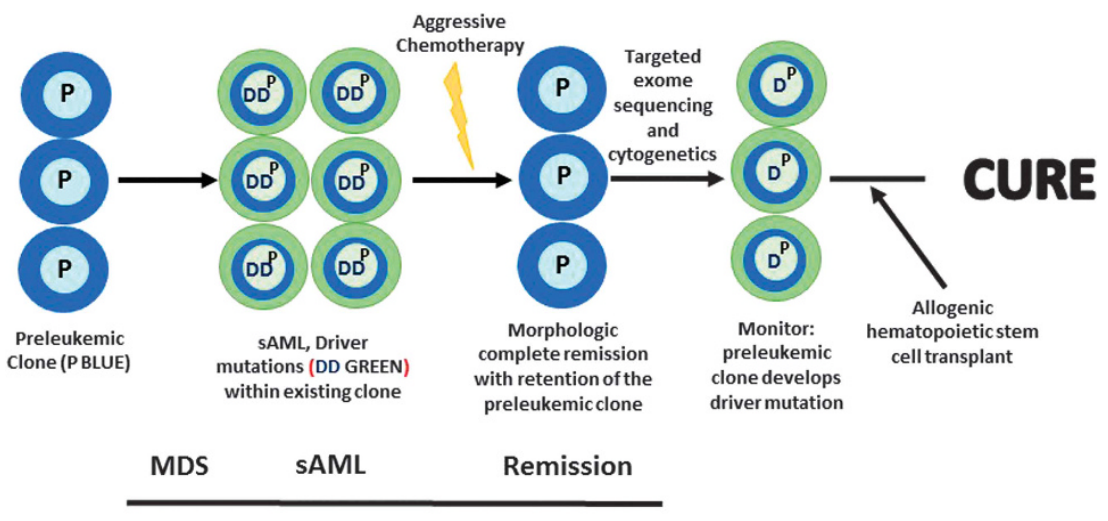

Clinical Diagnosis

Figure 2. Evolution to $M D S \rightarrow$ secondary $(s) A M L(s A M L) \rightarrow$ remission and potential therapeutic intervention.

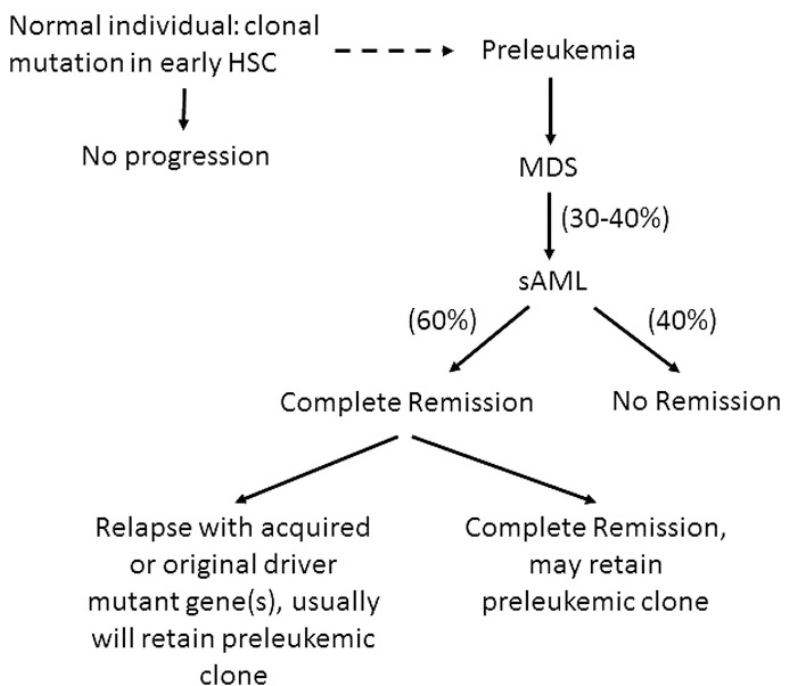

Figure 3. Hematopoiesis: Normal elderly individual \pm evolution to sAML. Normal elderly individuals can develop clonal hemtopoiesis marked by a mutation in their early hematopoietic stem cells (HSC). Some of these individuals will develop myelodysplastic syndrome (MDS); and with the acquisition of a Driver mutation, they can develop secondary $A M L$ ( $S A M L)$. These patients may go into complete morphologic remission but often retain their preleukemic clone. With relapse, they can either retain the original Driver mutation or acquire a new Driver mutation. Dotted line suggests that some normal elderly individuals with clonal hematopoiesis may develop MDS and SAML.

event. ${ }^{104,105}$ Many of the random mutations that occur in these cells affect non-critical genes (passenger genes) providing no growth advantage to these stem cells. Thus, 'bad luck' happens when a mutation occurs in a gene that provides a proliferative advantage to the hematopoietic cell. The resulting clone of cells has a greater chance to acquire additional mutations that might evolve into frank AML.

\section{SUMMARY}

In summary, the term 'preleukemia' has evolved over the years. Initially in the 1950s and 1960s, preleukemia was viewed as MDS. We now know that the clinical course as well as chromosomal and mutational changes of MDS are often markedly different from those present in de novo AML. Individuals with an inherited mutation of RUNX1, GATA2 or C/EBP in their germline have a very high chance of developing $A M L$; and thus have a preleukemic mutation. Also, previous treatment of a primary malignancy with either an alkylating drug or radiation therapy can result in a preleukemia that almost always progresses to AML. As outlined in Figure 3, very early hematopoietic stem cells can develop mutations that results in clonal hematopoiesis especially in those $>60$ years of age. In hematopoietically normal older individuals, this clone probably should not be called preleukemic. The incidence of evolution to $A M L$ in these individuals requires further study, but may be 0.5 to $1 \%$ per year. Quizzically, the mutations associated with MDS are often the same as those observed both in the normal elderly individual as well as the preleukemic clone in AML patients who are in morphologic complete remission. Development of overt $\mathrm{AML}$ requires Driver mutations. X-inactivation and DNA-sequencing studies showed that AML patients that obtained a complete morphologic remission can retain a preleukemic clone suggesting that these cells are resistant to normal ablative chemotherapy perhaps because they involve quiescent hematopoietic stem cells not easily killed by our standard chemotherapy. Patients whose leukemia evolves from an ancestral preleukemic clone, often will require therapy that exceeds our standard chemotherapy and perhaps monitoring of the preleukmic clone for acquisition of Driver mutations during remission may help to determine when aggressive therapy should be initiated. In conclusion, preleukemia might be defined as a condition that has modifying mutations in the bone marrow that either cause MDS or cause clonal hematopoietic expansion initially without disease but associated with progression to AML.

\section{CONFLICT OF INTEREST}

The authors declare no conflict of interest.

\section{ACKNOWLEDGEMENTS}

We thank the Melamed Family and Reuben Yeroushalmi for their generous support and Tim Babich for motivation to write this review. This work was also funded by the Leukemia Lymphoma Society of America, the Singapore Ministry of Health's National Medical Research Council (NMRC) under its Singapore Translational Research (STaR) Investigator Award to H. Phillip Koeffler (NMRC/STaR/0021/2014), Singapore Ministry of Education Academic Research Fund Tier 2 (MOE2013-T2-2-150), the NMRC Centre Grant awarded to National University Cancer Institute of Singapore (NMRC/CG/ 012/2013) and the National Research Foundation Singapore and the Singapore Ministry of Education under its Research Centres of Excellence initiatives.

\section{REFERENCES}

1 Block M, Jacobson LO, Bethard WF. Preleukemic acute human leukemia. J Am Med Assoc 1953; 152: 1018-1028. 
2 Koeffler HP. Myelodysplastic syndromes (preleukemia). Semin Hematol 1986; 23: 284-299.

3 Greenberg P, Cox C, LeBeau MM, Fenaux P, Morel P, Sanz G et al. International scoring system for evaluating prognosis in myelodysplastic syndromes. Blood 1997; 89: 2079-2088.

4 Brunning ROA, Germing U, Beau MM, Porwit A, Baumann I et al. Myelodysplastic syndromes. In: Swerdlow SH, International Agency for Research on Cancer, World Health Organization (eds). WHO classification of Tumours of Haematopoietic and Lymphoid Tissues; World Health Organization Classification of Tumours, 4th edn. International Agency for Research on Cancer: Lyon, France, 2008; p 439.

5 Tefferi A, Vardiman JW. Myelodysplastic syndromes. N Engl J Med 2009; 361 : 1872-1885.

6 Cazzola M, Della Porta MG, Travaglino E, Malcovati L. Classification and prognostic evaluation of myelodysplastic syndromes. Semin Oncol 2011; 38: 627-634.

7 Malcovati L, Hellstrom-Lindberg E, Bowen D, Ades L, Cermak J, Del Canizo C et al. Diagnosis and treatment of primary myelodysplastic syndromes in adults: recommendations from the European Leukemia Net. Blood 2013; 122: 2943-2964.

8 Papaemmanuil E, Gerstung M, Malcovati L, Tauro S, Gundem G, Van Loo P et al. Clinical and biological implications of driver mutations in myelodysplastic syndromes. Blood 2013; 122: 3616-3627.

9 Haferlach T, Nagata Y, Grossmann V, Okuno Y, Bacher U, Nagae G et al. Landscape of genetic lesions in 944 patients with myelodysplastic syndromes. Leukemia 2014; 28: 241-247.

10 Beutler E, West C, Johnson C. Involvement of the erythroid series in acute myeloid leukemia. Blood 1979; 53: 1203-1205.

11 Lyon MF. Sex chromatin and gene action in the mammalian X-chromosome. Am J Hum Genet 1962; 14: 135-148.

12 Busque L, Gilliland DG. X-inactivation analysis in the $1990 \mathrm{~s}$ : promise and potential problems. Leukemia 1998; 12: 128-135.

13 Gale RE, Linch DC. Clonality studies in acute myeloid leukemia. Leukemia 1998; 12: 117-120.

14 Beutler E, Yeh M, Fairbanks VF. The normal human female as a mosaic of X-chromosome activity: studies using the gene for C-6-PD-deficiency as a marker. Proc Natl Acad Sci USA 1962; 48: 9-16.

15 Beutler E, Collins Z, Irwin LE. Value of genetic variants of glucose-6-phosphate dehydrogenase in tracing the origin of malignant tumors. N Engl J Med 1967; 276: 389-391.

16 Linder D, Gartler SM. Glucose-6-phosphate dehydrogenase mosaicism: utilization as a cell marker in the study of leiomyomas. Science 1965; 150: 67-69.

17 Allen RC, Zoghbi HY, Moseley AB, Rosenblatt HM, Belmont JW. Methylation of Hpall and Hhal sites near the polymorphic CAG repeat in the human androgenreceptor gene correlates with X chromosome inactivation. Am J Hum Genet 1992; 51: 1229-1239.

18 Fialkow PJ. Use of genetic markers to study cellular origin and development of tumors in human females. Adv Cancer Res 1972; 15: 191-226.

19 Janssen JW, Buschle M, Layton M, Drexler HG, Lyons J, van den Berghe $\mathrm{H}$ et al. Clonal analysis of myelodysplastic syndromes: evidence of multipotent stem cell origin. Blood 1989; 73: 248-254.

20 Yoshida K, Sanada M, Shiraishi Y, Nowak D, Nagata Y, Yamamoto R et al. Frequent pathway mutations of splicing machinery in myelodysplasia. Nature 2011; 478: 64-69.

21 Papaemmanuil E, Cazzola M, Boultwood J, Malcovati L, Vyas P, Bowen D et al. Somatic SF3B1 mutation in myelodysplasia with ring sideroblasts. $N$ Engl J Med 2011; 365: 1384-1395.

22 Walter MJ, Shen D, Shao J, Ding L, White BS, Kandoth C et al. Clonal diversity of recurrently mutated genes in myelodysplastic syndromes. Leukemia 2013; 27: $1275-1282$.

23 Walter MJ, Shen D, Ding L, Shao J, Koboldt DC, Chen K et al. Clonal architecture of secondary acute myeloid leukemia. N Engl J Med 2012; 366: 1090-1098.

24 Bejar R, Stevenson K, Abdel-Wahab O, Galili N, Nilsson B, Garcia-Manero G et al. Clinical effect of point mutations in myelodysplastic syndromes. $N$ Engl J Med 2011; 364: 2496-2506.

25 Graubert TA, Shen D, Ding L, Okeyo-Owuor T, Lunn CL, Shao J et al. Recurrent mutations in the U2AF1 splicing factor in myelodysplastic syndromes. Nat Genet 2012; 44: 53-57.

26 Cancer Genome Atlas Research N. Genomic and epigenomic landscapes of adult de novo acute myeloid leukemia. N Engl J Med 2013; 368: 2059-2074.

27 Shih LY, Huang CF, Wang PN, Wu JH, Lin TL, Dunn P et al. Acquisition of FLT3 or $\mathrm{N}$-ras mutations is frequently associated with progression of myelodysplastic syndrome to acute myeloid leukemia. Leukemia 2004; 18: 466-475.

28 Dicker F, Haferlach C, Sundermann J, Wendland N, Weiss T, Kern W et al. Mutation analysis for RUNX1, MLL-PTD, FLT3-ITD, NPM1 and NRAS in 269 patients with MDS or secondary AML. Leukemia 2010; 24: 1528-1532.
29 Papaemmanuil E, Gerstung M, Bullinger L, Gaidzik VI, Paschka P, Roberts ND et al. Genomic classification and prognosis in acute myeloid leukemia. $N$ Engl J Med 2016; 374: 2209-2221.

30 Lindsley RC, Mar BG, Mazzola E, Grauman PV, Shareef S, Allen SL et al. Acute myeloid leukemia ontogeny is defined by distinct somatic mutations. Blood 2015; 125: 1367-1376.

31 Fialkow PJ, Janssen JW, Bartram CR. Clonal remissions in acute nonlymphocytic leukemia: evidence for a multistep pathogenesis of the malignancy. Blood 1991; 77: 1415-1417.

32 Busque L, Mio R, Mattioli J, Brais E, Blais N, Lalonde $\mathrm{Y}$ et al. Nonrandom $X$-inactivation patterns in normal females: Iyonization ratios vary with age. Blood 1996; 88: 59-65.

33 Gale RE, Wheadon H, Goldstone AH, Burnett AK, Linch DC. Frequency of clonal remission in acute myeloid leukaemia. Lancet 1993; 341: 138-142.

34 Gale RE, Fielding AK, Harrison CN, Linch DC. Acquired skewing of X-chromosome inactivation patterns in myeloid cells of the elderly suggests stochastic clonal loss with age. $\mathrm{Br} J$ Haematol 1997; 98: 512-519.

35 Williams DA, Lemischka IR, Nathan DG, Mulligan RC. Introduction of new genetic material into pluripotent haematopoietic stem cells of the mouse. Nature 1984; 310: 476-480.

36 Nash R, Storb R, Neiman P. Polyclonal reconstitution of human marrow after allogeneic bone marrow transplantation. Blood 1988; 72: 2031-2037.

37 Laurie CC, Laurie CA, Rice K, Doheny KF, Zelnick LR, McHugh CP et al. Detectable clonal mosaicism from birth to old age and its relationship to cancer. Nat Genet 2012; 44: 642-650.

38 Genovese G, Kahler AK, Handsaker RE, Lindberg J, Rose SA, Bakhoum SF et al. Clonal hematopoiesis and blood-cancer risk inferred from blood DNA sequence. N Engl J Med 2014; 371: 2477-2487.

39 Jaiswal S, Fontanillas P, Flannick J, Manning A, Grauman PV, Mar BG et al. Agerelated clonal hematopoiesis associated with adverse outcomes. N Engl J Med 2014; 371: 2488-2498.

40 McKerrell T, Park N, Moreno T, Grove CS, Ponstingl H, Stephens J et al. Leukemiaassociated somatic mutations drive distinct patterns of age-related clonal hemopoiesis. Cell Rep 2015; 10: 1239-1245.

41 Young AL, Challen GA, Birmann BM, Druley TE. Clonal haematopoiesis harbouring AML-associated mutations is ubiquitous in healthy adults. Nat Commun 2016; 7: 12484.

42 Busque L, Patel JP, Figueroa ME, Vasanthakumar A, Provost S, Hamilou Z et al. Recurrent somatic TET2 mutations in normal elderly individuals with clonal hematopoiesis. Nat Genet 2012; 44: 1179-1181.

43 Xie M, Lu C, Wang J, McLellan MD, Johnson KJ, Wendl MC et al. Age-related mutations associated with clonal hematopoietic expansion and malignancies. Nat Med 2014; 20: 1472-1478.

44 Kyle RA, Therneau TM, Rajkumar SV, Offord JR, Larson DR, Plevak MF et al. A long-term study of prognosis in monoclonal gammopathy of undetermined significance. N Engl J Med 2002; 346: 564-569.

45 Strati P, Shanafelt TD. Monoclonal B-cell lymphocytosis and early-stage chronic lymphocytic leukemia: diagnosis, natural history, and risk stratification. Blood 2015; 126: 454-462.

46 Martincorena I, Roshan A, Gerstung M, Ellis P, Van Loo P, McLaren S et al. Tumor evolution. High burden and pervasive positive selection of somatic mutations in normal human skin. Science 2015; 348: 880-886.

47 Fleischhacker M, Lee S, Spira S, Takeuchi S, Koeffler HP. DNA aneuploidy in morphologically normal colons from patients with colon cancer. Mod Pathol 1995; 8: 360-365.

48 Yakubovskaya MS, Spiegelman V, Luo FC, Malaev S, Salnev A, Zborovskaya I et al. High frequency of K-ras mutations in normal appearing lung tissues and sputum of patients with lung cancer. Int J Cancer 1995; 63: 810-814.

49 Cannon-Albright LA, Thomas A, Goldgar DE, Gholami K, Rowe K, Jacobsen M et al. Familiality of cancer in Utah. Cancer Res 1994; 54: 2378-2385.

50 Kerber RA, O'Brien E. A cohort study of cancer risk in relation to family histories of cancer in the Utah population database. Cancer 2005; 103: 1906-1915.

51 Goldin LR, Kristinsson SY, Liang XS, Derolf AR, Landgren O, Bjorkholm M. Familial aggregation of acute myeloid leukemia and myelodysplastic syndromes. J Clin Oncol 2012; 30: 179-183.

52 Song WJ, Sullivan MG, Legare RD, Hutchings S, Tan X, Kufrin D et al. Haploinsufficiency of CBFA2 causes familial thrombocytopenia with propensity to develop acute myelogenous leukaemia. Nat Genet 1999; 23: 166-175.

53 Hahn CN, Chong CE, Carmichael CL, Wilkins EJ, Brautigan PJ, Li XC et al. Heritable GATA2 mutations associated with familial myelodysplastic syndrome and acute myeloid leukemia. Nat Genet 2011; 43: 1012-1017.

54 Smith ML, Cavenagh JD, Lister TA, Fitzgibbon J. Mutation of CEBPA in familial acute myeloid leukemia. N Engl J Med 2004; 351: 2403-2407. 
55 Wlodarski MW, Hirabayashi S, Pastor V, Stary J, Hasle H, Masetti R et al. Prevalence, clinical characteristics, and prognosis of GATA2-related myelodysplastic syndromes in children and adolescents. Blood 2016; 127: 1387-1397.

56 Sellick GS, Spendlove HE, Catovsky D, Pritchard-Jones K, Houlston RS. Further evidence that germline CEBPA mutations cause dominant inheritance of acute myeloid leukaemia. Leukemia 2005; 19: 1276-1278.

57 Liew E, Owen C. Familial myelodysplastic syndromes: a review of the literature. Haematologica 2011; 96: 1536-1542.

58 Nickels EM, Soodalter J, Churpek JE, Godley LA. Recognizing familial myeloid leukemia in adults. Ther Adv Hematol 2013; 4: 254-269.

59 Babushok DV, Bessler M. Genetic predisposition syndromes: when should they be considered in the work-up of MDS? Best Pract Res Clin Haematol 2015; 28 : 55-68.

60 Churpek JE, Pyrtel K, Kanchi KL, Shao J, Koboldt D, Miller CA et al. Genomic analysis of germ line and somatic variants in familial myelodysplasia/acute myeloid leukemia. Blood 2015; 126: 2484-2490.

61 Chin DW, Sakurai M, Nah GS, Du L, Jacob B, Yokomizo T et al. RUNX1 haploinsufficiency results in granulocyte colony-stimulating factor hypersensitivity. Blood Cancer J 2016; 6: e379.

62 Yoshimi A, Toya T, Kawazu M, Ueno T, Tsukamoto A, lizuka H et al. Recurrent CDC25C mutations drive malignant transformation in FPD/AML. Nat Commun 2014; 5: 4770.

63 Shiba N, Hasegawa D, Park MJ, Murata C, Sato-Otsubo A, Ogawa C et al. CBL mutation in chronic myelomonocytic leukemia secondary to familial platelet disorder with propensity to develop acute myeloid leukemia (FPD/AML). Blood 2012; 119: 2612-2614.

64 Sun W, Downing JR. Haploinsufficiency of AML1 results in a decrease in the number of LTR-HSCs while simultaneously inducing an increase in more mature progenitors. Blood 2004; 104: 3565-3572.

65 Hsu AP, Sampaio EP, Khan J, Calvo KR, Lemieux JE, Patel SY et al. Mutations in GATA2 are associated with the autosomal dominant and sporadic monocytopenia and mycobacterial infection (MonoMAC) syndrome. Blood 2011; 118: 2653-2655.

66 Dickinson RE, Griffin H, Bigley V, Reynard LN, Hussain R, Haniffa M et al. Exome sequencing identifies GATA-2 mutation as the cause of dendritic cell, monocyte, B and NK lymphoid deficiency. Blood 2011; 118: 2656-2658.

67 Ostergaard P, Simpson MA, Connell FC, Steward CG, Brice G, Woollard WJ et al. Mutations in GATA2 cause primary lymphedema associated with a predisposition to acute myeloid leukemia (Emberger syndrome). Nat Genet 2011; 43: 929-931.

68 Wang X, Muramatsu H, Okuno Y, Sakaguchi H, Yoshida K, Kawashima N et al. GATA2 and secondary mutations in familial myelodysplastic syndromes and pediatric myeloid malignancies. Haematologica 2015; 100: e398-e401.

69 West RR, Hsu AP, Holland SM, Cuellar-Rodriguez J, Hickstein DD. Acquired ASXL1 mutations are common in patients with inherited GATA2 mutations and correlate with myeloid transformation. Haematologica 2014; 99: 276-281.

70 Connelly JP, Kwon EM, Gao Y, Trivedi NS, Elkahloun AG, Horwitz MS et al. Targeted correction of RUNX1 mutation in FPD patient-specific induced pluripotent stem cells rescues megakaryopoietic defects. Blood 2014; 124: 1926-1930.

71 lizuka H, Kagoya Y, Kataoka K, Yoshimi A, Miyauchi M, Taoka K et al. Targeted gene correction of RUNX1 in induced pluripotent stem cells derived from familial platelet disorder with propensity to myeloid malignancy restores normal megakaryopoiesis. Exp Hematol 2015; 43: 849-857.

72 Iwanski GB TN, Park DJ, Koeffler HPTherapy-related acute myelogenous leukemia. In: Wiernik PH GJ, Dutcher JP, Kyle Red. Neoplastic Diseases of the Blood, 5th edition. Springer: New York, NY, USA, Science+Business Media 2013; pp 455-486.

73 Pedersen-Bjergaard J, Philip P, Mortensen BT, Ersboll J, Jensen G, Panduro J et al. Acute nonlymphocytic leukemia, preleukemia, and acute myeloproliferative syndrome secondary to treatment of other malignant diseases. Clinical and cytogenetic characteristics and results of in vitro culture of bone marrow and HLA typing. Blood 1981; 57: 712-723.

74 Vardiman JW, Thiele J, Arber DA, Brunning RD, Borowitz MJ, Porwit A et al. The 2008 revision of the World Health Organization (WHO) classification of myeloid neoplasms and acute leukemia: rationale and important changesBlood 2009; 114: 937-951.

75 Rowley JD, Golomb HM, Vardiman JW. Nonrandom chromosome abnormalities in acute leukemia and dysmyelopoietic syndromes in patients with previously treated malignant disease. Blood 1981; 58: 759-767.

76 Kantarjian HM, Keating MJ, Walters RS, Smith TL, Cork A, McCredie KB et al. Therapy-related leukemia and myelodysplastic syndrome: clinical, cytogenetic, and prognostic features. J Clin Oncol 1986; 4: 1748-1757.

77 Gundestrup M, Klarskov Andersen M, Sveinbjornsdottir E, Rafnsson V, Storm HH, Pedersen-Bjergaard J. Cytogenetics of myelodysplasia and acute myeloid leukaemia in aircrew and people treated with radiotherapy. Lancet 2000; 356: 2158.
78 Pedersen-Bjergaard J. Insights into leukemogenesis from therapy-related leukemia. N Engl J Med 2005; 352: 1591-1594.

79 Le Beau MM, Albain KS, Larson RA, Vardiman JW, Davis EM, Blough RR et al. Clinical and cytogenetic correlations in 63 patients with therapy-related myelodysplastic syndromes and acute nonlymphocytic leukemia: further evidence for characteristic abnormalities of chromosomes no. 5 and 7. J Clin Oncol 1986; 4: 325-345.

80 Pedersen-Bjergaard J, Rowley JD. The balanced and the unbalanced chromosome aberrations of acute myeloid leukemia may develop in different ways and may contribute differently to malignant transformation. Blood 1994; 83: 2780-2786.

81 Rowley JD, Olney HJ. International workshop on the relationship of prior therapy to balanced chromosome aberrations in therapy-related myelodysplastic syndromes and acute leukemia: overview report. Genes Chromosomes Cancer 2002; 33: $331-345$.

82 Pedersen-Bjergaard J, Andersen MT, Andersen MK. Genetic pathways in the pathogenesis of therapy-related myelodysplasia and acute myeloid leukemia. Hematol Am Soc Hematol Educ Program 2007, 392-397.

83 Ok CY, Patel KP, Garcia-Manero G, Routbort MJ, Fu B, Tang G et al. Mutational profiling of therapy-related myelodysplastic syndromes and acute myeloid leukemia by next generation sequencing, a comparison with de novo diseases. Leuk Res 2015; 39: 348-354.

84 Wong TN, Ramsingh G, Young AL, Miller CA, Touma W, Welch JS et al. Role of TP53 mutations in the origin and evolution of therapy-related acute myeloid leukaemia. Nature 2015; 518: 552-555.

85 Kantarjian HM, Estey EH, Keating MJ. Treatment of therapy-related leukemia and myelodysplastic syndrome. Hematol Oncol Clin North Am 1993; 7: 81-107.

86 Dreyfus B. Preleukemic states. I. Definition and classification. II. Refractory anemia with an excess of myeloblasts in the bone marrow (smoldering acute leukemia). Nouv Rev Fr Hematol Blood Cells 1976; 17: 33-55.

87 Koeffler HP, Golde DW. Human myeloid leukemia cell lines: a review. Blood 1980; 56: 344-350.

88 Saarni MI, Linman JW. Preleukemia. The hematologic syndrome preceding acute leukemia. Am J Med 1973; 55: 38-48.

89 Churpek JE, Larson RA. The evolving challenge of therapy-related myeloid neoplasms. Best Pract Res Clin Haematol 2013; 26: 309-317.

90 Pui CH, Behm FG, Raimondi SC, Dodge RK, George SL, Rivera GK et al. Secondary acute myeloid leukemia in children treated for acute lymphoid leukemia. $N$ Engl J Med 1989; 321: 136-142.

91 Ratain MJ, Kaminer LS, Bitran JD, Larson RA, Le Beau MM, Skosey C et al. Acute nonlymphocytic leukemia following etoposide and cisplatin combination chemotherapy for advanced non-small-cell carcinoma of the lung. Blood 1987; 70: $1412-1417$.

92 Corces-Zimmerman MR, Hong WJ, Weissman IL, Medeiros BC, Majeti R. Preleukemic mutations in human acute myeloid leukemia affect epigenetic regulators and persist in remission. Proc Natl Acad Sci USA 2014; 111: 2548-2553.

93 Shlush LI, Zandi S, Mitchell A, Chen WC, Brandwein JM, Gupta V et al. Identification of pre-leukaemic haematopoietic stem cells in acute leukaemia. Nature 2014; 506: 328-333.

94 Klco JM, Miller CA, Griffith M, Petti A, Spencer DH, Ketkar-Kulkarni S et al. Association between mutation clearance after induction therapy and outcomes in acute myeloid leukemia. JAMA 2015; 314: 811-822.

95 Garg M, Nagata Y, Kanojia D, Mayakonda A, Yoshida K, Haridas Keloth S et al. Profiling of somatic mutations in acute myeloid leukemia with FLT3-ITD at diagnosis and relapse. Blood 2015; 126: 2491-2501.

96 Sun QY, Ding LW, Tan KT, Chien W, Mayakonda A, Lin DC et al. Ordering of mutations in acute myeloid leukemia with partial tandem duplication of MLL (MLL-PTD). Leukemia 2017; 31: 1-10.

97 Ploen GG, Nederby L, Guldberg P, Hansen M, Ebbesen LH, Jensen UB et al. Persistence of DNMT3A mutations at long-term remission in adult patients with AML. Br J Haematol 2014; 167: 478-486.

98 Wiseman DH, Williams EL, Wilks DP, Sun Leong $H$, Somerville TD, Dennis MW et al. Frequent reconstitution of IDH2R140Q mutant clonal multilineage hematopoiesis following chemotherapy for acute myeloid leukemia. Leukemia 2016; 30: 1946-1950.

99 Hirsch P, Zhang Y, Tang R, Joulin V, Boutroux H, Pronier E et al. Genetic hierarchy and temporal variegation in the clonal history of acute myeloid leukaemia. Nat Commun 2016; 7: 12475.

100 Hughes AE, Magrini V, Demeter R, Miller CA, Fulton R, Fulton LL et al. Clonal architecture of secondary acute myeloid leukemia defined by single-cell sequencing. PLoS Genet 2014; 10: e1004462.

101 Wong TN, Miller CA, Klco JM, Petti A, Demeter R, Helton NM et al. Rapid expansion of preexisting nonleukemic hematopoietic clones frequently follows induction therapy for de novo AML. Blood 2016; 127: 893-897. 
102 Griffith M, Miller CA, Griffith OL, Krysiak K, Skidmore ZL, Ramu A et al. Optimizing cancer genome sequencing and analysis. Cell Syst 2015; 1: 210-223.

103 Ivey A, Hills RK, Simpson MA, Jovanovic JV, Gilkes A, Grech A et al. Assessment of Minimal Residual Disease in Standard-Risk AML. N Engl J Med 2016; 374: 422-433.

104 Tomasetti C, Vogelstein B. Cancer etiology. Variation in cancer risk among tissues can be explained by the number of stem cell divisions. Science 2015; 347: 78-81.

105 Vogelstein B, Papadopoulos N, Velculescu VE, Zhou S, Diaz Jr LA, Kinzler KW. Cancer genome landscapes. Science 2013; 339: 1546-1558.
cC)(1) (2) This work is licensed under a Creative Commons AttributionNonCommercial-ShareAlike 4.0 International License. The images or other third party material in this article are included in the article's Creative Commons license, unless indicated otherwise in the credit line; if the material is not included under the Creative Commons license, users will need to obtain permission from the license holder to reproduce the material. To view a copy of this license, visit http:// creativecommons.org/licenses/by-nc-sa/4.0/

(c) The Author(s) 2017 